University of Nebraska - Lincoln

DigitalCommons@University of Nebraska - Lincoln

USDA National Wildlife Research Center - Staff Publications
U.S. Department of Agriculture: Animal and Plant Health Inspection Service

2019

Potential role of wildlife in the USA in the event of a foot-andmouth disease virus incursion

Vienna R. Brown

Oak Ridge Institute for Science and Education, vienna.r.brown@aphis.usda.gov

Sarah N. Bevins

USDA APHIS Wildlife Services

Follow this and additional works at: https://digitalcommons.unl.edu/icwdm_usdanwrc

Part of the Natural Resources and Conservation Commons, Natural Resources Management and Policy Commons, Other Environmental Sciences Commons, Other Veterinary Medicine Commons, Population Biology Commons, Terrestrial and Aquatic Ecology Commons, Veterinary Infectious Diseases Commons, Veterinary Microbiology and Immunobiology Commons, Veterinary Preventive Medicine, Epidemiology, and Public Health Commons, and the Zoology Commons

Brown, Vienna R. and Bevins, Sarah N., "Potential role of wildlife in the USA in the event of a foot-andmouth disease virus incursion" (2019). USDA National Wildlife Research Center - Staff Publications. 2262. https://digitalcommons.unl.edu/icwdm_usdanwrc/2262

This Article is brought to you for free and open access by the U.S. Department of Agriculture: Animal and Plant Health Inspection Service at DigitalCommons@University of Nebraska - Lincoln. It has been accepted for inclusion in USDA National Wildlife Research Center - Staff Publications by an authorized administrator of DigitalCommons@University of Nebraska - Lincoln. 


\title{
Potential role of wildlife in the USA in the event of a foot-and-mouth disease virus incursion
}

\author{
Vienna R Brown, ${ }^{\oplus 1}$ Sarah N Bevins²
}

\begin{abstract}
Foot-and-mouth disease (FMD) is caused by foot-and-mouth disease virus (FMDV) which affects domestic and wild cloven-hoofed species. The FMD-free status of the USA and the tremendous economic impact of a virus incursion motivated the development of this evaluation of the potential role of wildlife in the event of a virus introduction. Additionally, this manuscript contains a summary of US vulnerabilities for viral incursion and persistence which focuses specifically on the possible role of wildlife. The legal movement of susceptible live animals, animal products, by-products and animal feed containing animal products pose a risk of virus introduction and spread. Additionally, the illegal movement of FMD-susceptible animals and their products and an act of bioterrorism present additional routes where FMDV could be introduced to the USA. Therefore, robust surveillance and rapid diagnostics in the face of a possible introduction are essential for detecting and controlling FMD as quickly as possible. Wildlife species and feral pigs present an added complexity in the case of FMDV introduction as they are typically not closely monitored or managed and there are significant logistical concerns pertaining to disease surveillance and control in these populations. Recommendations highlight the need to address existing knowledge gaps relative to the potential role of wildlife in FMDV introduction events.
\end{abstract}

\section{Introduction}

Foot-and-mouth disease (FMD) is caused by foot-andmouth disease virus (FMDV) which infects clovenhoofed animals, including cattle, sheep, goats and pigs, as well as various wild species. ${ }^{1}$ The primary routes of transmission are inhalation of infectious virus, direct and indirect contact with infected animals and exposure to contaminated fomites. Clinical disease manifests as vesicle formation on the tongue, hard palate, dental pad, lips, gums, muzzle, coronary band, interdigital space and (in females) on the teats. ${ }^{2-4}$ These lesions lead to weight loss, lameness, lethargy and a reduction in milk yield. ${ }^{5}$ Additionally, death due to myocardial necrosis

Veterinary Record (2019)

'Oak Ridge Institute for Science and Education (ORISE), National Wildlife Research Center, Oak Ridge, Tennessee, USA

2Wildlife Services, National Wildlife Research Center (NWRC), Animal and Plant Health Inspection Service, United States Department of Agriculture (USDA), Fort Collins, Washington, District of Columbia, USA doi: 10.1136/vr.104895

E-mail for correspondence: Oak Ridge Institute for Science and Education (ORISE), Oak Ridge, TN, United States ; vienna.r.brown@aphis.usda.gov

Provenance and peer review Not commissioned; externally peer reviewed.

Received February 20, 2018 Revised February 13, 2019 Accepted March 29, 2019 has been reported in young animals. ${ }^{6}$ There have been eight different outbreaks in the USA since the first reported introduction in 1870, with the last reported case of FMD occurring in 1929 in California. ${ }^{7}$ There are seven immunological serotypes of FMDV, each with a multitude of topotypes, genetic lineages and strains enzootic in Africa, Asia and parts of South America. ${ }^{8-11}$

FMD is considered to be one of the most important animal diseases in the world because of the significant financial burden associated with this disease in both endemic and FMD-free countries. ${ }^{12}$ Estimates indicate that FMD costs between US $\$ 6.5$ and US $\$ 21$ billion annually in endemic countries, with the principal costs attributed to production losses and vaccination and outbreaks of FMD can cost FMD-free countries more than US $\$ 1.5$ billion annually. ${ }^{13}$ A number of models approximate the cost associated with an introduction of FMD into the USA; however, outcomes are variable as they are dependent on a number of factors, including species of detection; size of the operation implicated in the index case; presence or absence of transmission events to other livestock of the same species, an alternative species, or wildlife or feral animals; geographical location within the country; and rapidity of detection and deployment of disease control efforts. ${ }^{14-16}$ 
Notably, based on information from the 2001 FMD outbreak in the UK, the total cost may, in fact, be much larger. ${ }^{17}$ More than $6,000,000$ animals were depopulated and the direct costs to the public and private sectors combined are approximated at over US $\$ 10.5$ billion. This outbreak was initiated through the feeding of contaminated, untreated waste to pigs and was then introduced to sheep on a nearby property and readily disseminated through the marketing and movement of sheep. ${ }^{18} 19$ In 2010, there was an FMD outbreak in Japan in a densely cattle and pig populated region and 290,000 animals were depopulated in order to control the epidemic, resulting in compensation costs of US $\$ 550$ million for the value of culled livestock. ${ }^{20}$ Furthermore, South Korea experienced five outbreaks of FMD between 2000 and 2011 which resulted in over US $\$ 3.5$ billion in economic losses and ultimately resulted in the loss of FMD-free status. ${ }^{21}$

FMD is not a zoonotic pathogen but it is a reportable animal disease to the World Organisation for Animal Health (OIE) and virus detection can bring about substantial trade restrictions and tremendous economic losses. This manuscript provides a brief description of domestic livestock production within the continental USA as well as an overview of FMDV-susceptible feral and wildlife species on the landscape. While our primary focus is on FMD in wildlife, management of domestic livestock was included as the livestockwildlife interface is a risk for spillover which would significantly complicate control strategies in the event of a virus introduction. A summary of vulnerabilities for US viral introduction and persistence is provided and, ultimately, recommendations are made for further research based on determined gaps in knowledge.

\section{Domestic livestock}

Domestic livestock, specifically cattle, sheep, goats and pigs, are all susceptible to infection with FMDV and their density and distribution across the USA, in addition to commonly used management practices, are important components that would play a role in the event of an FMDV introduction into the USA. The number of cattle and calves in the USA is estimated to be 93 million animals with the beef industry valued at nearly $\$ 68$ billion ${ }^{22}$ and the dairy industry, as measured by farm gate receipts, was estimated to be valued at $\$ 34$ billion in $2016 .{ }^{23}$ Cattle are found in all 50 states with Texas, Nebraska, Kansas, California and Oklahoma serving as the top five states for cattle and calf production in 2015, accounting for nearly 40 per cent of all production. Sales of sheep and goats and their products totalled nearly $\$ 705$ million in the USA in 2007 , according to the 2007 Census of Agriculture Report, reported by the National Agriculture Statistics Service. ${ }^{24}$ The sheep population in the USA was conservatively estimated to be 5.2 million head in January 2018 and the majority of sheep are raised west of the Mississippi River with
Texas, California, Colorado, Wyoming and Utah being the five largest producers of sheep and their products. ${ }^{25}$ The goat population in the USA was approximated at 3.5 million animals that are used for meat, milk and fibre purposes based on data obtained from the 2002 agricultural census. ${ }^{26}$ Texas, Tennessee, California, Oklahoma and Georgia are the top five goat-producing states and California has the largest population of dairy goats in the USA. The estimated population of domestic pigs in the USA is 65 million, with Iowa, North Carolina, Minnesota, Illinois and Indiana being the five top porkproducing states annually. ${ }^{27}$ The 2012 USDA Census of Agriculture reported the hog and pig industry to have sales of $\$ 22.5$ billion.

For ruminants, the majority of meat animals are managed on pasture or rangeland for the duration of their lives or until the final stage whence they are congregated in a feedlot setting for finishing, whereas dairy animals are typically managed in an open lot or barn setting to facilitate milk collection. There is an opportunity for interaction with other domestic livestock or wildlife in either setting, although the pasture or range grazed animals would be more likely to encounter feral or wild species. It is important to note that outbreaks in animals grazed on pasture or rangeland would be much more difficult to control, either via vaccination or depopulation, as compared with concentrated animals in a drylot or feedlot setting. The commercial pig industry is managed entirely indoors with no access to, or interaction with, other domestic livestock or wildlife; however, backyard pigs may have ample opportunity to interact with a variety of domestic and wild species.

Retrospective analyses from the 2001 outbreak of FMD in Great Britain determined that the spatial distribution, size and species composition on farms heavily influenced the observed pattern of disease spread and regional variability. ${ }^{28}$ The initial spread of the outbreak is believed to have been driven by the movement of sheep, likely partially attributable to difficulty detecting FMD infection in sheep as compared with cattle or pigs. ${ }^{29}$ Several modelling analyses demonstrated that markets, and other high-density, high-dissemination facilities, such as dealers and slaughterhouses, played an instrumental role in viral spread. ${ }^{29}{ }^{30}$ Simulations suggest that the contamination of markets is crucial for a large epidemic event ${ }^{29}$ and not surprisingly, reduced animal mixing was found to decrease the number of cases, the number of culled animals, and shorten the overall duration of the epidemic. ${ }^{28}$ Also of consequence, cattle were determined to be a key species in the 2001 FMD outbreak after initial spread by sheep. ${ }^{31}$ Resultant from this finding, Buhnerkempe and colleagues $^{32}$ modelled the impact of movement and animal density on a nationwide FMD-like disease outbreak in the USA and found that cattle movement restrictions from infected counties 
were found to effectively contain outbreaks as compared with a national moratorium on animal movement. These findings suggest that animal movements from infected regions have the capacity to contribute to an outbreak event and effectively disseminate the virus.

\section{Feral pigs}

Feral pigs (Sus scrofa) include released and escaped domestic pigs, truly wild European boars and their hybrids, and are believed to have become established in the continental USA in the 1400s. ${ }^{33-35}$ Experts estimate that over 6 million feral pigs roam within at least 35 states in the USA with California, Florida, Oklahoma and Texas having the largest populations. ${ }^{36} \mathrm{~A}$ side-byside experimental infection with FMDV was performed to compare the clinical manifestation and transmission capacity of feral and domestic pigs. Domestic and feral pigs were both found to be highly susceptible to infection with FMDV and developed similar clinical signs, although feral pigs had higher tolerance and the vesicular lesions were more difficult to detect as a result of their thicker, darker skin. ${ }^{37}$ This experimental infection demonstrated that feral pigs are potential hosts for FMDV due to their acute susceptibility, their capacity to shed large quantities of virus orally, their close interactions with domestic livestock, and their unrestrained, minimally managed lifestyle.

\section{Wildlife species}

Along with domestic livestock, wild cloven-hoofed species are also susceptible to FMDV and the USA is home to a number of wild ungulates. Experimental infections have demonstrated susceptibility in whitetailed deer (Odocoileus virginianus), ${ }^{38} 39$ mule deer (Odocoileus hemionus), ${ }^{40}$ elk (Cervus canadensis), ${ }^{41}$ bison (Bison bison) ${ }^{41}$ and pronghorn antelope (Antilocapra americana). ${ }^{42}$ All of these species show similar clinical signs as domestic livestock and are able to transmit the virus to uninfected animals of the same species and naïve cattle, less elk which were demonstrated to be more resistant to infection. ${ }^{41}$ Despite acute susceptibility to FMDV in many wild North American ungulates, it is unlikely these species would serve as a true viral reservoir. ${ }^{43}$ More probably, the virus would spill over from infected domestic livestock to susceptible wild ungulates, would be transmitted through the herd and then would be self-limiting as the animals became infected and then recovered. This is supported by historical observations where FMDV disappears from local wildlife populations following its eradication in domestic species. ${ }^{43}$ However, frequent interactions between infected wildlife and domestic livestock could result in recurrent spillover and spillback events which could heavily complicate virus control. Furthermore, it is difficult to determine with certainty the role wildlife may or may not play in a natural setting as there are a number of factors that are not accounted for in experimental infections such as density of each susceptible species on the landscape, intraspecies interaction, proximity of wildlife species to one another and to domestic livestock, as well as factors related to the environment that may affect viral stability and transmissibility.

Determining population estimates for each wild cloven-hoofed animal in the USA is a tremendous undertaking and a national database with this information is not available. In the event of an outbreak, state game agencies would have population estimates for ungulates in that particular region which could be used to develop a strategy for managing exposed and infected wildlife.

\section{Emergency preparedness for the USA}

The government and private animal sectors of the USA are acutely aware of the consequences that may result from the introduction of FMDV and as such, a variety of foreign animal disease and FMD experts have assembled documents that address the different components of an outbreak scenario. ${ }^{44-48}$ The Red Book states that a wildlife management plan would be developed immediately following the identification of an FMD index case in livestock. ${ }^{46}$ The density and distribution of susceptible wildlife species would be evaluated as well as the social structure, habitat, contact with livestock and potential duration of viral exposure as part of a larger wildlife risk assessment. Additionally, documents providing guidance on wildlife management in the USA in the event of an FMD outbreak were developed in 2001 by the International Association of Fish and Wildlife Agencies and by the USDOI National Park Service in response to the FMD outbreak in the UK. ${ }^{49}$ Updating and adding detail to these guidelines for FMD surveillance and response in wildlife could be beneficial for future emergency response operations. Depending on the findings of the risk assessment, wildlife management principles and tools would be used to reduce the interaction of wildlife and livestock and to prevent wildlife from spreading disease.

Additionally, the North American Foot-and-Mouth Disease Vaccine Bank at Plum Island Animal Disease Center maintains an inventory of antigens that are derived from the virus strains that are currently circulating globally. ${ }^{50}$ However, it is not logistically feasible to maintain an up-to-date vaccine bank with all the possible FMD serotypes and subtypes on a scale that would allow for immediate vaccination of all animals involved in the outbreak or those potentially exposed.

The current vaccines available for FMDV are inactivated whole virus preparations that are supplemented with adjuvant. ${ }^{1}$ These vaccines have been found to be highly efficacious; however, there are concerns as their preparation requires the inactivation of large volumes of live, active virus, and thus a high 
biocontainment facility. Furthermore, these vaccines are sometimes contaminated with non-structural proteins making it difficult to differentiate between vaccinated and naturally infected animals (also known as DIVA); however, continued work has led to the development of more robust DIVA diagnostics. ${ }^{51}$

Importantly, in 2012 the first FMD vaccine delivered by replication-defective human adenovirus type 5 vector (Ad5-FMD) was licensed for use in cattle in the USA in the event of an outbreak scenario..$^{52} 53$ This vaccine was produced as the result of a large public-private enterprise between the Department of Homeland Security, USDA, Antelope Valley Biologics and GenVec. The Ad5-FMD vaccine is engineered to encode structural proteins Vp0, Vp1 and Vp3 from the A24 Cruzeiro FMDV strain and contains an adjuvant..$^{52} 53$ This method is advantageous for several reasons, including safety which allows the vaccine to be produced on the US mainland and the ability to differentiate vaccinated animals from those naturally infected. However, this new, conditionally licensed vaccine can only be used for strains that are heterologous to the A24 Cruzeiro strain.

The Department of Homeland Security is currently producing master seed viruses for 10 other serotypes considered to be high and medium-priority strains by the World Reference Laboratory for Foot-andMouth Disease using the human adenovirus platform. Limited investments are being made in multivalent and combinatorial vaccines. The Department of Homeland Security has also evaluated several other rapid vaccine platforms for use in an outbreak.

From a diagnostic perspective, both ELISA and quantitative PCR are highly sensitive and swift techniques that can be used on samples derived from any species and allow for the rapid detection of antigen or amplification of a select region of RNA, respectively. ${ }^{54}$ Virus isolation methods are used to detect live, infectious virus which can be subjected to further assays to determine the exact serotype or subtype of FMDV, although this method is much slower. ${ }^{55}$

Despite detailed regulations, extensive documents outlining proposed control and eradication strategies, the presence of a variety of FMDV antigens in the Vaccine Bank and diagnostics that can be used across a variety of species, an FMD outbreak in the USA may be difficult to contain. Animal rearing in high-density settings and routine transportation could facilitate an FMDV outbreak on a large scale that would likely be difficult to control and eradicate.

\section{Summary of US vulnerabilities for FMDV introduction or persistence}

\section{Risk of introduction into the USA}

FMDV could be introduced into the USA through a variety of routes. A disease outbreak is most likely to result from (1) the legal movement of live animals or their products, by-products or animal feed containing animal products, (2) the illegal movement of live animals and their products, or (3) an intentional viral release in an act of bioterrorism. These routes are deemed to be the most probable means of introduction because of factors related to infected animal shedding patterns (quantity and duration), viral stability, historical viral outbreaks related to the feeding of FMDV-contaminated feed to susceptible animal species (which has resulted in several FMDV importations into the USA, including the 1924 outbreak) and current global instability. ${ }^{56}$ KnightJones and colleagues ${ }^{57}$ describe risk reduction to be closely linked to FMD incidence in both neighbouring and trade countries, highlighting the importance of regulations surrounding the importation of animals and their products. They further conclude that unregulated movement (illegal importation) poses an important threat of introduction as well.

\section{Legal movement of live animals}

Live animal importation serves as a potential route of introduction because of the acute susceptibility of a large number of domestic and wild cloven-hoofed animals and the patterns of viral shedding which present an opportunity for transmission. Live clovenhoofed animals are not permitted to be imported from any country that is endemic for FMD; however, this rule may change owing to concerns that many important, exotic species in zoos are becoming inbred and new genes are necessary to revive the US captive population. Currently, the USA only imports live cloven-hoofed animals from Mexico, Canada, Australia and New Zealand, and zoo animals from FMD-free countries (9 CFR Part 93).

During 2015, the Southern and Northern Border port directors, respectively, report that cattle were the only cloven-hoofed animals that were imported from Mexico, and cattle, small ruminants, pigs, bison and wild animals were the ungulates imported from Canada. The vast majority of cattle imported from Mexico were destined for meat production with small numbers imported for research, competition, breeding or rodeo use. Cloven-hoofed animals imported from Canada were destined primarily for breeding and feeding purposes and direct to slaughter. In addition to Mexico and Canada, the USA accepts cattle and small ruminant imports from Australia and New Zealand following pre-export and post-export quarantines. No cattle or small ruminants were imported from Australia or New Zealand in 2015. ${ }^{58}$

A wide variety of commonly maintained zoo animals and wildlife species are susceptible to infection with FMDV, specifically the order Artiodactyla which includes giraffes, antelopes, sheep, goats, camels and camelids, and pigs, among others. ${ }^{59}$ Official zoos tend to adhere to principles of biosecurity and any unusual clinical signs or an actual disease outbreak would likely be readily detected. Furthermore, these facilities typically 
have a perimeter fence to prevent domestic animals and native wildlife species from interacting with zoo animals. However, wildlife reserves, sanctuaries, parks and high fence properties (which are facilities with high fences that typically contain animals used for hunting) often contain both native and non-native wildlife species that are susceptible to FMDV infection which are managed much less intensively and may be rarely, if ever, observed by personnel with expertise in disease recognition and diagnosis. Moreover, it is likely that the species confined within the fenced area are comingled and that they have contact with out-of-fence wildlife species. In many instances, animals within these properties are able to escape and become feral where they certainly could interact with both domestic livestock and wildlife species.

The process for the movement of captive wild species across state lines and between facilities is highly variable because of disparities in state laws, the species being transported and the specific regulations associated with both facilities involved in the transaction. Limited oversight on many animal rearing facilities may result in comingling of FMD-susceptible animals that are both native and exotic, with some potentially being captive while others are truly wild, and fencing may be inadequate to prevent accidental escape. Additionally, in the event of an outbreak scenario it would be extremely challenging to ascertain the breadth and magnitude of the role wildlife may play as both native and non-native species would be a concern. High fence properties containing exotic and wild species from abroad often have animals that escape from this captive setting which could pose a tremendous threat to native species and significantly complicate a disease outbreak. ${ }^{60-63}$ For example, there are a number of breeding populations of exotic species, such as oryx (Oryx species), Barbary sheep (Ammotragus lervia) and nilgai antelope (Boselaphus tragocamelus) in the USA, especially Texas. Of note, nilgai and oryx are acutely susceptible to FMDV and develop severe lesions when infected. ${ }^{64}{ }^{65}$ Furthermore, nilgai are well established in parts of Texas and north-eastern Mexico and are believed to contribute to the spread of cattle tick fever across the landscape, ${ }^{66}$ advancing the notion that non-native species can complicate disease transmission patterns. For a thorough review of FMDV susceptibility in various wildlife species, see ref ${ }^{43}$.

A number of cloven-hoofed animals are imported into the USA annually ${ }^{46}$ and in the event an FMD-infected animal was imported, the outbreak potential would be heavily dependent on where the animal was transported following importation. Based on simulation modelling, an infected animal that was imported direct to slaughter would have less capacity for disease transmission as compared with a breeding animal, an animal imported for competition or rodeo use, or into a feedlot setting. ${ }^{28-30}$

Legal movement of animal products, by-products and animal feed containing animal products

Currently the USA imports a wide variety of animal products, by-products and animal feed containing animal products from countries all over the world. Animal products, by-products and animal feed containing animal products from FMD-endemic countries must be mitigated prior to importation using a mitigation strategy that is approved, such as heat (at a specific temperature for a specified duration), $\mathrm{pH}$ or chemical treatment. The importation of fresh, unprocessed animal products, by-products and animal feed containing animal products from FMD-endemic countries is strictly prohibited. Imports of this nature from FMD-free regions typically require a zoo sanitary certificate attesting to the product identity, country of origin and that the product has not been exposed to unauthorised animal products. Of all animal products, by-products and feed imports, those used to feed animals are the most important as they represent the highest risk for FMDV introduction.

\section{Illegal movement of live animals and their products}

Illegally imported products and specimens from domestic livestock may be confiscated by the US Department of Homeland Security Customs and Border Protection (CBP). Data provided by CBP depict products and specimens from domestic livestock and cervids that were confiscated in the cargo or express courier environment, which includes both FedEx and DHL, or via international mail facilities, including the US postal service. Between calendar years 2012 and 2016, over 117,000 products and specimens derived from domestic livestock and cervids were confiscated by CBP. Pig products made up nearly 60 per cent of all seizures while bovids, which include cattle, bison, buffalo and yak, made up approximately 40 per cent; sheep, goats, cervids and unspecified ruminants each made up 1 per cent or less of all confiscations (figure 1).

The data provided by CBP depict that the continent of origin for the majority of products and specimens confiscated by CBP is Asia ( 52 per cent), which includes a number of countries endemic for FMD. ${ }^{67}$ Africa and South America, both of which are endemic for FMDV in some or all regions, were the continent of origin for a total of 2 per cent of all confiscated products and specimens. Products and specimens from Europe and North America comprised approximately 36 per cent of all confiscations, both of which are FMD free. These data are summarised in figure 2.

The US Fish and Wildlife Service (FWS) is responsible for the confiscation of illegally imported wildlife and their products. Data obtained from FWS demonstrated 


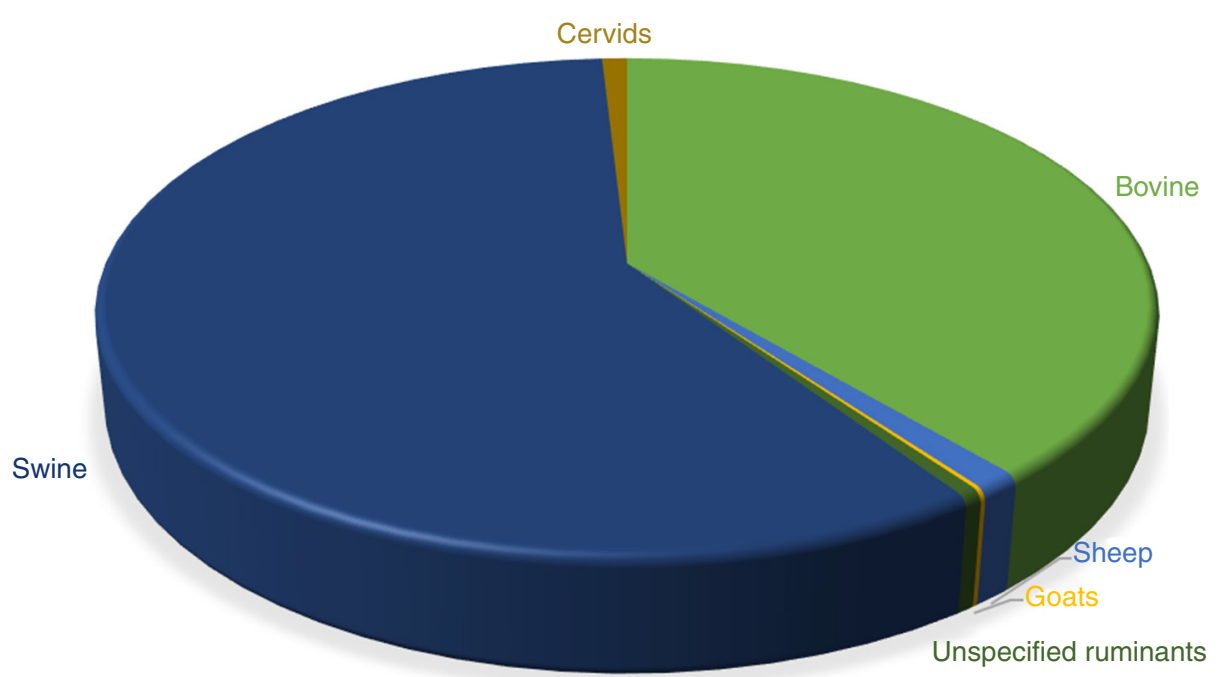

Figure 1 A pie chart depicting the types of products confiscated by US Customs and Border Protection between 2012 and 2016 (n=117,308).

that a variety of products were seized between 2006 and 2016, ranging from jewellery to medicinal products to parts or whole carcasses. For the purpose of the risk of FMDV introduction into the USA, carcasses, meat, skin, hooves and bones were included in the data summary. It is important to note that each confiscation was treated as a single event (eg, $10 \mathrm{lb}$ of seized meat was treated identically to $100 \mathrm{lb}$ of seized meat) unless the measuring unit was a raw number (eg, 10 hides were counted as 10, not as 1).

The majority of products seized by FWS were those that originated in other North American countries (55 per cent), specifically Canada and Mexico. The African continent was responsible for a quarter of all cloven-hoofed species product confiscation and
South America, Europe, Asia, Australia and unknown comprised the remaining 20 per cent. These data confirm the suspicion that illegal wildlife and wildlife product importation pose a risk for FMDV introduction as nearly half of all confiscated products were derived from continents which are endemic for FMDV (or of unknown origin).

Notably, over a 10-year period for the entire USA, less than 2000 wildlife products were confiscated $(n=1848)$. In contrast, flights arriving at Roissy-Charles de Gaulle airport in Paris from west and central Africa on a single carrier (Air France) were estimated to harbour 272 tons of wildlife meat each year. ${ }^{68}$ While France likely has more flights originating directly from west and central African countries than the USA, and while there

Continent of origin for products from domestic livestock and cervids confiscated between 2012-2016

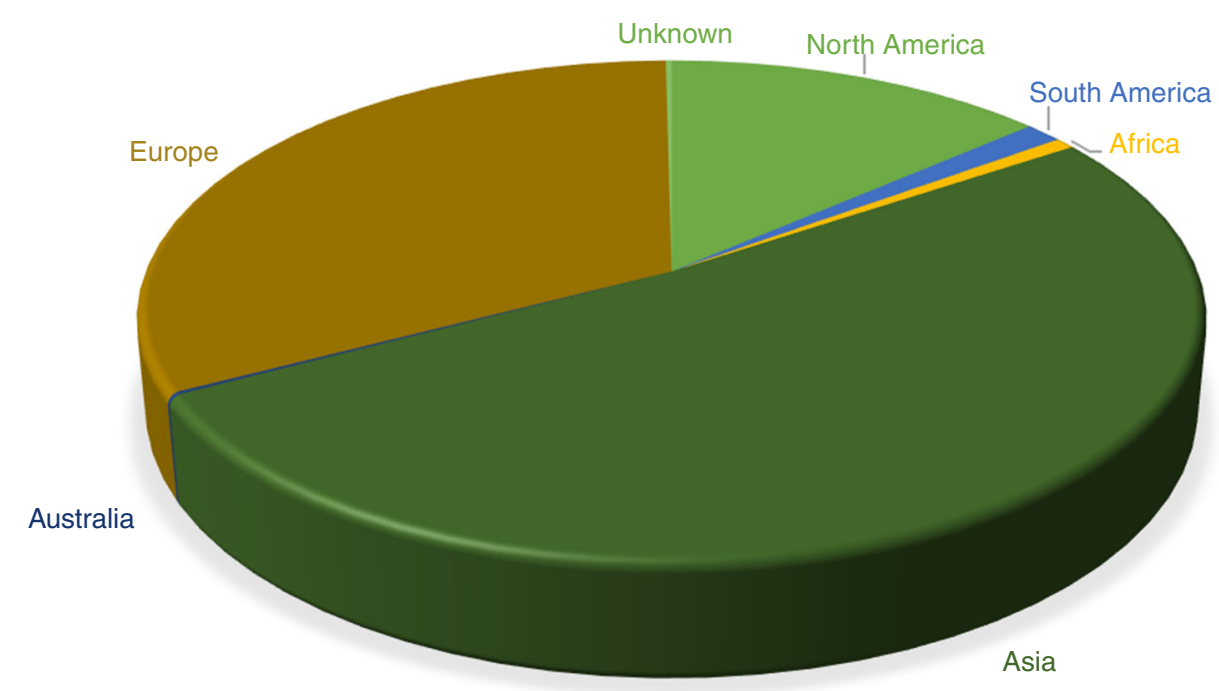

Figure 2 A pie chart depicting the continent of origin for the products and specimens confiscated by the US Customs and Border Protection between 2012 and 2016 $(n=117,308)$. 
were likely more wildlife seizures than were captured by the official FWS data, the low number of wildlife confiscations still suggests that resources for inspection are likely not sufficient to catch many of the products entering the USA illegally.

\section{Bioterrorism}

Bioterrorism, the intentional release or dissemination of bacteria, viruses or toxins that cause morbidity or mortality events in humans, other animals or plants, presents an alternative route for FMD introduction into the USA. The breadth of domestic and wildlife species susceptible to infection, high morbidity, low infectious dose, high shedding capability of infected animals, ease of viral collection and crippling economic impact associated with an introduction makes FMDV a potential candidate for bioterrorism. This risk provides an impetus to maintain vigilant surveillance protocols in both domestic livestock and wildlife species to ensure rapid detection and differential diagnoses.

\section{Factors that complicate eradication efforts following introduction}

The introduction of FMDV into the USA would be devastating for both livestock and producers. If the event was limited to domestic livestock, there is historical precedent demonstrating that control and eradication is possible; however, in the event FMDV was either introduced to feral or wild species or spilled over from domestic livestock, successful control of the disease would become more complicated. ${ }^{69}$

As outlined by Rhyan and Spraker, ${ }^{70}$ substantial political, technical and logistical issues arise related to disease surveillance and control in wildlife. Often, baseline information on the disease and host population is lacking and obtaining a reliable population estimate can be problematic. Passive surveillance activities are fraught with complication because of reliance on public reporting, survival behaviours making many wild species highly stoic and frequent predation and scavenging of a carcass following the death of an animal. Active surveillance requires capture or kill techniques which are both expensive, invasive and, in many cases, highly controversial. In the event of a disease outbreak, effective disease containment, efficacious vaccinations and/or depopulation techniques in a given area can also present financial and logistical challenges.

\section{Feral pigs}

Pigs appear to be quite tolerant to FMDV infection via inhalation of naturally produced aerosols, ${ }^{71}$ which has been substantiated by the demonstration that the porcine upper respiratory tract is less permissive to viral inoculation as compared with the upper gastrointestinal tract. ${ }^{72}$ However, once infected, pigs shed 30-100 times more virus from the oropharyngeal tonsil epithelium and are efficient at spreading FMDV to cattle especially, and to a lesser extent, sheep and goats. ${ }^{337374}$ Feral pigs may serve as a potential host if FMDV was introduced into the USA. ${ }^{3375}$ Their uncontrolled movement could result in rapid transmission events to domestic livestock and wildlife species. A study that evaluated the impact of a FMDV introduction from a wild pig into a commercial livestock premise in California concluded that FMDV introduction into a dairy or beef cattle herd could result in a rapidly spreading outbreak. ${ }^{76}$ Additionally, modelling of FMDV transmission in a wild pig-domestic cattle ecosystem in Australia demonstrated that in the majority of simulations in which cattle-to-cattle, cattle-to-pig or pig-to-cattle transmission occurred, FMDV was able to establish and transmit. ${ }^{77}$ In this modelling scenario, FMD was self-limiting in the wild pigs; however, the most rapid disease control method targeted both cattle and wild pigs. In the Strandzha Mountains in Bulgaria, wild boar were found to play a role, albeit temporally and spatially limited, in the FMDV transmission cycle. ${ }^{78} 79$ The magnitude of wild boar involvement in FMDV transmission is believed to be heavily dependent on the population size and density as well as environmental conditions during viral introduction; however, sylvatic FMD outbreaks in wild boar and other wild ungulates are likely possible in parts of Europe, especially in regions with large, dense populations of FMD-susceptible wildlife. Further examination of the role of wildlife in the spread of FMD in Bulgaria determined that limited spread of the virus is possible in wildlife populations and increased interaction between domestic and wild animals as well as increased population densities may lead to lengthened viral circulation. ${ }^{80}$ This highlights the need for robust feral pig population estimates throughout the USA.

Furthermore, feral pigs have been found to be translocated and intentionally released by citizens in an attempt to create local hunting opportunities. ${ }^{33} 75$ These types of activities would also complicate FMDV eradication in the event feral pigs became infected and could facilitate rapid and widespread dissemination of the virus across the USA. It is important to note that experimental infections in both domestic and feral pigs suggest that pigs are unlikely to be competent longterm carriers of infectious FMDV. ${ }^{3781}$ However, feral pigs could become infected and significantly complicate disease control efforts in domestic livestock via spillover and spillback events.

\section{Wildlife species}

Experimental infections have demonstrated the susceptibility of a number of wild cloven-hoofed species in the USA; however, multiple other species of clovenhoofed animals are native to the USA, such as moose (Alces alces), bighorn sheep (Ovis canadensis), mountain goats (Oreamnos americanus), and caribou (Rangifer tarandus) and muskoxen (Ovibus moschatus) in Alaska. 
These species are likely to be susceptible to FMDV to varying degrees, although no experimental work has been conducted. While experimental challenges are useful for understanding host-pathogen dynamics, they fail to provide other crucial epidemiological information relative to interactions between the host, pathogen and environment. Furthermore, wildlife density on the landscape both independent of, and in relation to, domestic livestock is fundamental in order to gain a full understanding of the dynamic. In addition, zoos, wildlife parks and high fence properties (many in Texas) often contain multipleFMDV susceptible species.

Aside from African Cape buffalo, no other wildlife species has been shown to play an important role in the maintenance of FMDV, despite all seven FMDV serotypes having been found in wildlife. ${ }^{43}$ Clinical disease associated with FMDV infection in wildlife species ranges from asymptomatic to lethal infections, with the majority of gross and histopathological lesions resembling those seen in domestic species. Usually outbreaks in wildlife are resultant from passive spillover events from domestic livestock, and despite decades of research, no evidence exists to suggest that wildlife species serve as a true reservoir (except for Cape buffalo).

Most FMD outbreaks in wildlife are resultant from passive spillover events from domestic livestock, including in 1924 when there was an FMDV outbreak in cattle that spilled over into the mule deer population in California, resulting in the culling of 22,000 deer, 10 per cent of which exhibited typical FMDV lesions. ${ }^{82}$ Rapid culling of both cattle and deer resulted in viral eradication from both domestic and wild species soon thereafter. Furthermore, a model simulating FMDV spread in Texas found that both deer and feral pigs may amplify virus and contribute to viral maintenance. ${ }^{83}$ These findings contradict other available literature stating that wildlife species are, for the most part, not true reservoirs; however, pathogen transmission is heavily dependent on the location(s) of introduction, density of susceptible animals, types of animals infected and shedding infectious virus, proximity of infected and naïve animals and many other factors, suggesting that the possibility of short-term FMD maintenance in wildlife populations exists.

\section{Discussion and concluding remarks}

Due to the breadth of species that are susceptible to FMDV infection and the large number of countries with endemic disease, an introduction of FMDV, either accidental or purposeful, presents a threat to the USA. Furthermore, re-establishing FMD-free status following an introduction would be substantially more complex if the virus spills over (or is introduced) to feral pigs or wildlife species. Many regulations and systems are in place to prevent the importation of FMDV while importing animals and their products via legal channels.
The illegal importation of animals and their products, both wild and domestic species, as well as bioterrorism is difficult to control, manage or regulate without substantial investment in personnel and resources and represents a risk for FMDV importation and subsequent introduction.

\section{Future directions and recommendations}

FMDV introduction in feral pigs and/or wildlife species would heavily complicate eradication. ${ }^{70}$ One potential way to address FMD introduction in wildlife would be to use existing hunter check station infrastructure to build a means of surveilling wildlife for FMD. Hunter check stations are typically administered at the state level and were established and maintained primarily for regulatory and population management data. Some are currently used to evaluate deer for chronic wasting disease, bovine tuberculosis and other pathogens, but also serve to provide population information to wildlife management agencies. In the event of an FMDV introduction or if spillover into deer was of heightened concern, guidelines could be developed to incorporate surveillance for FMD into hunter check stations. Hunter checkstations could be used over broad areas, but if more targeted wildlife surveillance was required, the USDA/ APHIS/Wildlife Services (WS)/National Wildlife Disease Program (NWDP) has trained biologists and emergency first responders that could target surveillance efforts to specific areas in a coordinated effort with a domestic animal outbreak response. Field biologists working with wildlife and feral pigs could be further trained to identify clinical signs of FMDV and examine trapped or euthanised wildlife and feral pigs for the presence of vesicular lesions. In the event an animal is observed with such lesions, further differential diagnostics could be taken to determine aetiology.

Zoos as well as animal parks, sanctuaries and wildlife reserves, as well as other operations, often maintain FMD-susceptible species which could further complicate eradication methods in the event of an outbreak. Depending on the type of operation, there is often very little oversight on the types and numbers of animals maintained, and in some cases these exotic species escape and establish reproductively active populations outside of captivity. The role that exotic wildlife would play in FMD transmission and maintenance given a viral introduction is unknown; however, control strategies would certainly be further complicated. Enhanced databases that maintain what types of animals are kept and the numbers maintained, for both domestic livestock and exotic species, would be useful to evaluate risk and inform control strategies. Despite its utility, there are significant privacy concerns that may necessitate the use of non-traditional approaches. For example, a spatial microsimulation model was created using domestic pig farms which 
attempts to balance privacy concerns with the need for robust data. ${ }^{84}$

Most data suggest that FMD will ultimately be selflimiting in wildlife and that effective control of FMDV in domestic livestock will result in sufficient protection for both livestock and wildlife species without necessitating intervention on the wildlife side. ${ }^{43}$ FMD would likely also be self-limiting in feral pigs based on the data from FMD-infected wild boar abroad ${ }^{79}$; however, these animals do pose a unique problem because of their gregarious nature, large litter size and abundant geographical distribution, in addition to their susceptibility to FMDV and robust shedding patterns following infection. Additionally, they have been shown to interact freely with domestic pigs in some situations ${ }^{35}$ and likely other domestic livestock. The current USDA/ APHIS/Feral Swine Damage Management Program is designed to reduce damage associated with feral pigs through a variety of means, including removal. Disease surveillance programmes, including the USDA/ APHIS/WS/NWDP, are in place for several pathogens that pose a risk to humans, domestic livestock and wildlife; however, the programme could include FMD surveillance in feral pigs in the event of an introduction or outbreak.

Active wildlife surveillance could potentially incorporate thermography to evaluate hoof temperature $^{40}$ or baited cotton ropes that could be evaluated for the presence of live or dead virus in saliva. ${ }^{85} 86$ Rope-in-a-bait sampling has been experimentally evaluated using laboratory inoculated wild boar and comparisons between the baited rope and direct swabbing were found to have similar sensitivity. ${ }^{87}$ An additional non-invasive screening method is aerosol sampling which has been shown to be an effective means of detecting FMDV in expired air from several species of domestic livestock. ${ }^{88} 89$ Virus detection from airway sampling preceded clinical disease in most cases which makes it a particularly useful tool for early detection. ${ }^{89}$ Thermography, baited rope and aerosol sampling are all non-invasive techniques and could be used in conjunction with other surveillance methods. Studies on using baited cotton ropes for wildlife FMDV surveillance could identify robust and efficient methodologies in diagnostic testing and experimental designs for their use on the landscape. Depending on terrain and climate it is likely that variation will exist for optimal placement in different geographical regions and with differing wildlife densities and these need to be elucidated prior to use. Aerosol sampling in wildlife would present significant challenges as individual animals would need to be caught and restrained; however, it may be a favourable surveillance method, especially with endangered or charismatic wildlife species.

Despite the presence of an FMD vaccine bank and a conditionally licensed product in the USA in the event of an outbreak, the use of vaccines is quite controversial. As per the OIE guidelines, the return to free status following an outbreak of FMD requires substantial oversight and is a lengthy process, ${ }^{90}$ which is exacerbated by the use of vaccines. Administering vaccines necessitates significant resources and infrastructure aside from having sufficient vaccine quantities that can be delivered quickly, including regulatory framework; animal identification and tracking systems; and surveillance and control measures such as biosecurity, cleaning and disinfection protocols. Furthermore, the interface between state and federal agencies as well as private animal owners is quite complex and potentially reflects competing interests. The determination of vaccine efficacy in wildlife species may be important in the event the virus was to be introduced or spilled over, especially if large, charismatic or endangered species were involved. To date, FMD vaccines have not been evaluated in any wildlife species.

The USA (and other FMD-free countries) have operated under a 'stamping out' protocol following the introduction of FMDV which involves mass depopulation of infected and potentially exposed animals. This method has been adopted due, in part, to the inability of the current vaccines to prevent primary infection, ${ }^{9192}$ difficulty with viral persistence ${ }^{92} 93$ and because of the implications vaccine usage has on international trade of domestic animal products. ${ }^{94}$ Stamping out is considered to be highly efficacious when the virus is in a somewhat focal region and restricted to domestic species or a small number of wildlife (eg, 1924 outbreak in California). ${ }^{95}$ However, stamping out becomes complicated if the virus is widespread, infects a large number of animals, or feral pigs and/or wildlife are heavily involved for several reasons: (1) cost, (2) environmental damage associated with the disposal of a huge number of carcasses, (3) inability to find and remove all infected animals, (4) valuable genetics, especially for native wildlife species and zoo animals, and (5) public perception associated with large-scale removal of charismatic wildlife species. Therefore, avoiding widespread infection in wildlife is key. This could be accomplished, in part, by having a clear strategy for vigilant surveillance in wildlife, combined with continued training for field personnel in differential diagnosis of vesicular diseases and validated diagnostics for wildlife.

In summary, our review of the literature related to FMDV infection in wildlife species in the USA has generated a number of recommendations that would be useful in an outbreak scenario and to better control and eradicate the virus in the event it spilled into wild or feral animals. Databases containing information about the types and numbers of cloven-hoofed animals maintained at each property, including both domestic livestock and exotic wildlife imported for sport or pleasure, are essential for rapidly assessing risk or mobilising control efforts following an outbreak. 
The development of non-invasive surveillance methods, such as baited ropes, aerosol sampling and thermography, is important as traditional sampling methods for wild and feral species are both labour and cost intensive which minimises its utility. Studying vaccine efficacy in susceptible US wildlife species, such as mule and white-tailed deer, bison, pronghorn antelope and a number of zoo animals, may be a useful research endeavour in the event of a national outbreak scenario in which a stamping out approach would be infeasible. Additionally, characterising and validating PCR methods in wildlife would be crucial to the development of robust diagnostics.

Acknowledgements Thanks to Drs Peter Fernandez and Jack Rhyan for their expertise and for their internal review of this manuscript. Dr Tom Gidlewski provided stimulating conversation and facilitated contact with other area experts. Finally, we thank a multitude of USDA APHIS, especially Dr Vivek Kamath, USDOI Fish and Wildlife Service, and USDHS Customs and Border Protection personnel for providing data relevant to live animals as well as confiscated wild animal products and specimens and domestic species products and specimens, respectively. This research was supported in part by an appointment to the US Department of Homeland Security (DHS) Research Participation Program administered by the Oak Ridge Institute for Science and Education (ORISE) through an interagency agreement between the US Department of Energy (DOE) and DHS. ORISE is managed by Oak Ridge Associated Universities (ORAU) for the DOE under contract number DE-SC0014664.

Funding The authors have not declared a specific grant for this research from any funding agency in the public, commercial or not-for-profit sectors.

Disclaimer All opinions expressed in this paper are the authors' and do not necessarily reflect the policies and views of DHS, DOE or ORISE.

Competing interests None declared.

(C) British Veterinary Association 2019. No commercial re-use. See rights and permissions. Published by BMJ.

\section{References}

1 Grubman MJ, Baxt B. Foot-and-mouth disease. Clin Microbiol Rev 2004;17:465-93.

2 Kitching RP. Clinical variation in foot and mouth disease: cattle. Revue Scientifique et Technique de l'OIE 2002;21:499-504.

3 Kitching RP, Alexandersen S. Clinical variation in foot and mouth disease: pigs. Revue Scientifique et Technique de l'OIE 2002;21:513-8.

4 Kitching RP, Hughes GJ. Clinical variation in foot and mouth disease: sheep and goats. Revue Scientifique et Technique de l'OIE 2002;21:505-12.

5 Alexandersen S, Zhang Z, Donaldson Al, et al. The pathogenesis and diagnosis of foot-and-mouth disease. J Comp Pathol 2003;129:1-36.

6 Stenfeldt C, Pacheco JM, Borca MV, et al. Morphologic and phenotypic characteristics of myocarditis in two pigs infected by foot-and mouth disease virus strains of serotypes O or A. Acta Vet Scand 2014;56:1-7

7 McCauley EH, New JC, Aulaqui NA, et al. A study of the potential economic impact of foot-and-mouth disease in the United States. St. Paul: University of Minnesota, 1979.

8 Bachrach HL. Foot-and-mouth disease. Annu Rev Microbiol 1968;22:201-44.

9 Domingo E, Baranowski E, Escarmís C, et al. Foot-and-mouth disease virus. Comp Immunol Microbiol Infect Dis 2002;25:297-308.

10 Jamal SM, Belsham GJ. Foot-and-mouth disease: past, present and future. Vet Res 2013;44:116-14

11 Brito BP, Rodriguez LL, Hammond JM, et al. Review of the Global Distribution of Foot-and-Mouth Disease Virus from 2007 to 2014. Transbound Emerg Dis 2017;64:316-32

12 International Federation for Animal Health (IFAH). The costs of animal disease: Oxford Analytica, 2012

13 Knight-Jones TJD, Rushton J. The economic impacts of foot and mouth disease - What are they, how big are they and where do they occur? Prev Vet Med 2013;112:161-73.

14 Elbakidze L, Highfield L, Ward M, et al. Economics analysis of mitigation strategies fo FMD introduction in highly concentrated animal feeding regions. Review of Agricultural Economics 2009;31:931-50.

15 Cozzens T, Gebhardt K, Shwiff SA, et al. Modeling the economic impact of feral swinetransmitted foot-and-mouth disease: A case study from Missouri. Proceedings from the 24th Vertebrate Pest Conference 2010:308-11.

16 Miller M, Liu L, Shwiff S, et al. Macroeconomic impact of foot-and-mouth disease vaccinations in the Midwestern United States: A general equilibrium simulation. Transbound Emerg Dis 2019;66:156-65.

17 National Audit Office (NAO). The 2001 outbreak of foot and mouth disease. Comptroller and Auditor General, HC 939 Session 2001-2002, 2002. Available: https://www.nao. org.uk/report/the-2001-outbreak-of-foot-and-mouth-disease/ [Accessed 22 Aug 2016].

18 Ferguson NM, Donnelly CA, Anderson RM. The foot-and-mouth epidemic in Great Britain: pattern of spread and impact of interventions. Science 2001;292:1155-60.
19 Davies G. The foot and mouth disease (FMD) epidemic in the United Kingdom 2001 Comp Immunol Microbiol Infect Dis 2002;25:331-43.

20 Muroga N, Hayama Y, Yamamoto T, et al. The 2010 foot-and-mouth disease epidemic in Japan. J Vet Med Sci 2012:74:399-404

21 Park J-H, Lee K-N, Kim S-M, et al. Reemergence of foot-and-mouth disease, South Korea, 2000-2011. Emerg Infect Dis 2014;20:2158-61.

22 National Cattlemen's Beef Association (NCBA). Industry statistics. 2018. http://www. beefusa.org/beefindustrystatistics.aspx

23 USDA ERS. 2016. https://data.ers.usda.gov/reports.aspx?ID=17843\#P0cf6954b5d9 d475cb1b125489e935cec_2_17iTOROx0

24 USDA NASS. Overview of the United States sheep and goat industry. 2011. http://usda. mannlib.cornell.edu/usda/current/ShpGtInd/ShpGtInd-08-09-2011.pdf

25 USDA NASS. Sheep and goats. 2018. http://usda.mannlib.cornell.edu/usda/current/ SheeGoat/SheeGoat-01-31-2018.pdf

26 USDA APHIS. The goat industry: Structure, concentration, demand and growth 2002. https://www.aphis.usda.gov/animal_health/emergingissues/downloads/ goatreport090805.pdf

27 USDA NASS. Overview of the United States hog industry. 2015. http://usda.mannlib. cornell.edu/usda/current/hogview/hogview-10-29-2015.pdf

28 Keeling MJ, Woolhouse ME, Shaw DJ, et al. Dynamics of the 2001 UK foot and mouth epidemic: stochastic dispersal in a heterogeneous landscape. Science 2001;294:813-7.

29 Green DM, Kiss IZ, Kao RR. Modelling the initial spread of foot-and-mouth disease through animal movements. Proceedings of the Royal Society B: Biological Sciences 2006;273:2729-35.

30 Ortiz-Pelaez A, Pfeiffer DU, Soares-Magalhães RJ, et al. Use of social network analysis to characterize the pattern of animal movements in the initial phases of the $2001 \mathrm{foot}$ and mouth disease (FMD) epidemic in the UK. Prev Vet Med 2006;76:40-55.

31 Chis Ster I, Ferguson NM. Transmission parameters of the 2001 foot and mouth epidemic in Great Britain. PLoS One 2007;2:e502.

32 Buhnerkempe MG, Tildesley MJ, Lindström T, et al. The impact of movements and animal density on continental scale cattle disease outbreaks in the United States. PLOS One 2014;9:e91724

33 Hutton T, DeLiberto T, Owen S, et al. Disease risks associated with increasing feral swine numbers and distribution in the United States. Michigan Bovine Tuberculosis Bibliography and Database 2006;59.

34 Pimental D. Environmental and economic costs of vertebrate species invasions into the United States: Managing Vertebrate Invasive Species: Proceedings of an International Symposium, 2007;38:1-8.

35 Wyckoff AC, Henke SE, Campbell TA, et al. Feral swine contact with domestic swine: a serologic survey and assessment of potential for disease transmission. I Wildl Dis 2009; 45:422-9.

36 USDA APHIS. Expanding feral swine populations. 2017. https://www.aphis.usda. gov/aphis/ourfocus/wildlifedamage/programs/nwrc/sa_spotlight/expanding+feral+ swine+populations

37 Mohamed F, Swafford S, Petrowski H, et al. Foot-and-mouth disease in feral swine: susceptibility and transmission. Transbound Emerg Dis 2011;58:358-71.

38 McVicar JW, Sutmoller P, Ferris DH, et al. Foot-and-mouth disease in white-tailed deer: Clinical signs and transmission in the laboratory: Proceedings of the Annual Meeting of the United States Animal Health Association, 1974;78:169-80.

39 Moniwa M, Embury-Hyatt C, Zhang Z, et al. Experimental foot-and-mouth disease virus infection in white tailed deer. J Comp Pathol 2012;147:330-42.

40 Dunbar MR, Johnson SR, Rhyan JC, et al. Use of infrared thermography to detect thermographic changes in mule deer (Odocoileus hemionus) experimentally infected with foot-and-mouth disease. I Zoo Wildl Med 2009;40:296-301.

41 Rhyan J, Deng M, Wang H, et al. Foot-and-mouth disease in North American bison (Bison bison) and elk (Cervus elaphus nelsoni): susceptibility, intra- and interspecies transmission, clinical signs, and lesions. J Wildl Dis 2008;44:269-79.

42 Rhyan J, McCollum M, Gidlewski T, et al. Foot-and-mouth disease in a small sample of experimentally infected pronghorn (Antilocapra americana). 2016;52.

43 Weaver GV, Domenech J, Thiermann AR, et al. Foot-and-mouth disease: a look from the wild side. J Wildl Dis 2013;49:759-85.

44 Roth JA, Stumbaugh A, Spickler AR, et al. NAHEMS guidelines: Vaccination for contagious diseases: Veterinary Microbiology and Preventive Medicine Reports 2014;6.

45 Roth JA, Spickler AR. FMD vaccine surge capacity for emergency use in the United States. White paper prepared by the Center for Food Security and Public Health at lowa State University, 2014.

46 USDA APHIS. Foot-and-mouth disease response plan: The Red Book. 2014. https:// www.aphis.usda.gov/animal_health/emergency_management/downloads/fmd_ responseplan.pdf

47 USDA APHIS. Foreign animal disease preparedness and response plan. 2015. https:// www.aphis.usda.gov/animal_health/emergency_management/downloads/ documents manuals/fadprep_manual_2.pdf

48 Roth JA. Preparedness and control challenges for an outbreak of foot and mouth disease in lowa: White paper prepared by the Center for Food Security and Public Health at lowa State University, 2016

49 National Park Service (NPS). Interim: Foot-and-mouth disease response plan: National Park Service, 2001. http://npshistory.com/publications/wildlife/FMD-response.pdf

50 DeHaven WR. Foot-and-mouth disease vaccine production for use in the United States, 2017. http://nppc.org/wp-content/uploads/2017/06/FMD-Vaccine-Bank.pdf

51 Uttenthal ÅSE, Parida S, Rasmussen TB, et al. Strategies for differentiating infection in vaccinated animals (DIVA) for foot-and-mouth disease, classical swine fever and avian influenza. Expert Rev Vaccines 2010;9:73-87.

52 Grubman MJ, Diaz-San Segundo F, Dias CCA, et al. Use of replication-defective adenoviruses to develop vaccines and bio-therapeutics against foot-and-mouth disease. Future Virol 2012;7:767-78. 
53 Robinson L, Knight-Jones TID, Charleston B, et al. Global foot-and-mouth disease research update and gap analysis: 3 - Vaccines. Transbound Emerg Dis 2016;63:30-41.

54 OIE. Chapter 2.1.8: Foot and mouth disease (infection with foot and mouth disease virus). OIE Terrestrial Manual, 2017:1-32.

55 Longjam N, Deb R, Sarmah AK, et al. A brief review on diagnosis of foot-and-mouth disease of livestock: Conventional to molecular tools. Vet Med Int 2011;2011:1-17.

56 Grundmann O. The current state of bioterrorist attack surveillance and preparedness in the U.S. RiskManagement and Healthcare Policy. 2014;7:177-87.

57 Knight-Jones TJD, Robinson L, Charleston B, et al. Global foot-and-mouth disease research update and gap analysis: 1 - Overview of global status and research needs. Transbound Emerg Dis 2016;63:3-13.

58 Veterinary Services Process Streamlining System. Animal Import Module Reports 2015.

59 Thomson GR, Vosloo W, Bastos ADS. Foot and mouth disease in wildlife. Virus Res 2003;91:145-61.

60 Demarais S, Osborn DA, Jackley JJ. Exotic big game: A controversial resource: Society for Range Management, 1990;12:121-5.

61 Nelle S. Exotics: At home on the range in Texas. Rangelands 1992;14:77-80.

62 Traweek M, Welch R. Exotics in Texas: Texas Parks and Wildlife Department, 1992. http://www.shsu.edu/dotAsset/4159f592-d8dc-4857-a513-bc793606c64f.pdf

63 Butler MJ, Teaschner AP, Ballard WB, et al. Wildlife ranching in North Americaarguments, issues, and perspectives. Wildl Soc Bull 2005;33:381-9.

64 Frölich K, Hamblin C, Jung S, et al. Serologic surveillance for selected viral agents in captive and free-ranging populations of Arabian oryx (Oryx leucoryx) from Saudi Arabia and the United Arab Emirates. J Wildl Dis 2005;41:67-79.

65 Sujatha K, Srilatha C. A note on an outbreak of foot and mouth disease in captive Nilgai. Zoos' Print Journal 2007:22:2733.

66 Foley AM, Goolsby JA, Ortega-S. A, et al. Movement patterns of nilgai antelope in South Texas: Implications for cattle fever tick management. Prev Vet Med 2017;146:166-72

67 OIE. Foot-and-mouth disease (FMD), 2018. http://www.oie.int/en/animal-health-inthe-world/animal-diseases/Foot-and-mouth-disease/

68 Chaber A-L, Allebone-Webb S, Lignereux Y, et al. The scale of illegal meat importation from Africa to Europe via Paris. Conserv Lett 2010;3:317-21.

69 Arzt J, Baxt B, Grubman MJ, et al. The pathogenesis of foot-and-mouth disease II: Viral pathways in swine, small ruminants, and wildlife; myotropism, chronic syndromes, and molecular virus-host interactions. Transboundary and EmergingDiseases. Transbound Emerg Dis 2011:58:305-26.

70 Rhyan JC, Spraker TR. Emergence of diseases from wildlife reservoirs. Vet Pathol 2010;47:34-9

71 Sellers RF. Quantitative aspects of the spread of foot-and-mouth disease. Veterinary Bulletin 1971:41:431-9.

72 Stenfeldt C, Diaz-San Segundo F, de los Santos T, et al. The pathogenesis of foot-and mouth disease in pigs. Front Vet Sci 2016b;3:1-12.

73 Donaldson Al, Ferris NP. Sites of release of airborne foot-and-mouth disease virus from infected pigs. Res Vet Sci 1980;29:315-9.

74 Stenfeldt C, Pacheco JM, Rodriguez LL, et al. Early events in the pathogenesis of footand-mouth disease in pigs; identification of oropharyngeal tonsils as sites of primary and sustained viral replication. PLoS One 2014b;9:e106859.

75 Witmer GW, Sanders RB, Taft AC. Feral swine - Are they a disease threat to livestock in the United States? USDA National Wildlife Research Center - Staff Publications, 2003;292.

76 Pineda-Krch M, O'Brien JM, Thunes C, et al. Potential impact of introduction of foot-andmouth disease from wild pigs into commercial livestock premises in California. Am J Vet Res 2010;71:82-8.

77 Ward MP, Garner MG, Cowled BD. Modelling foot-and-mouth disease transmission in a wild pig-domestic cattle ecosystem. Aust Vet J 2015;93:4-12.
78 Valdazo-Gonzalez B, Knowles NJ, Wadsworth J, et al. Foot-and-mouth disease in Bulgaria. Vet Rec 2011;168:247

79 Alexandrov T, Stefanov D, Kamenov P, et al. Surveillance of foot-and-mouth disease (FMD) in susceptible wild life and domestic ungulates in Southeast of Bulgaria following a FMD case in wild boar. Vet Microbiol 2013;166:84-90.

80 Dhollander S, Belsham GJ, Lange M, et al. Assessing the potential spread and maintenance of foot-and-mouth disease virus infection in wild ungulates: general principles and application to a specific scenario in Thrace. Transbound Emerg Dis 2016;63:165-74.

81 Stenfeldt C, Pacheco JM, Smoliga GR, et al. Detection of foot-and-mouth disease virus RNA and capsid protein in lymphoid tissues of convalescent pigs does not indicate existence of a carrier state. Transbound Emerg Dis 2016;63:152-64.

82 Keane C. The outbreak of foot and mouth disease among deer in the Stanislaus National Forest: Monthly Bulletin of the Department of Agriculture, 1927;16:213-26.

83 Ward MP, Laffan SW, Highfield LD. The potential role of wild and feral animals as reservoirs of foot-and-mouth disease. Prev Vet Med 2007;80:9-23.

84 Burdett CL, Kraus BR, Garza SJ, et al. Simulating the distribution of individual livestock farms and their populations in the United States: an example using domestic swine (Sus scrofa domesticus) farms. PLoS One 2015;10:e0140338.

85 Vosloo W, Morris J, Davis A, et al. Collection of oral fluids using cotton ropes as a sampling method to detect foot-and-mouth disease virus infection in pigs. Transbound Emerg Dis 2015;62:e71-e75.

86 Knight-Jones TJD, Robinson L, Charleston B, et al. Global foot-and-mouth disease research update and gap analysis: 4 - Diagnostics. Transbound Emerg Dis 2016;63:42-8.

87 Mouchantat S, Haas B, Böhle W, et al. Proof of principle: Non-invasive sampling for early detection of foot-and-mouth disease virus infection in wild boar using a rope-ina-bait sampling technique. Vet Microbiol 2014;172:329-33.

88 Amaral Doel CMF, Gloster J, Valarcher J-F. Airborne transmission of foot-and-mouth disease in pigs: Evaluation and optimisation of instrumentation and techniques. Vet 2009;179:219-24.

89 Pacheco JM, Brito B, Hartwig E, et al. Early detection of foot- and-mouth disease virus from infected cattle using a dry filter air sampling system. Transbound Emerg Dis 2017;64:564-73.

90 OIE. Chapter 8.8: Infection with foot-and-mouth disease virus. OIE Terrestrial Animal Health Code, 2018:1-24.

91 Doel TR, Williams L, Barnett PV. Emergency vaccination against foot-and-mouth disease: Rate of development of immunity and its implications for the carrier state. Vaccine 1994:12:592-600.

92 Stenfeldt C, Hartwig EJ, Smoliga GR, et al. Contact challenge of cattle with foot-and mouth disease virus validates the role of the nasopharyngeal epithelium as the site of primary and persistent infection. mSphere 2018;3:e00493-18.

93 Doel TR. FMD vaccines. Virus Res 2003;91:81-99.

94 Sutmoller P, Barteling SS, Olascoaga RC, et al. Control and eradication of foot-andmouth disease. Virus Res 2003;91:101-44.

95 Arzt J, Juleff N, Zhang Z, et al. The pathogenesis of foot-and-mouth diseases I: vira pathways in cattle. Transbound Emerg Dis 2011;58:291-304

96 Alexandersen S, Brotherhood I, Donaldson Al. Natural aerosol transmission of footand-mouth disease virus to pigs: minimal infectious dose for strain $\mathrm{O}_{1}$ Lausanne. Epidemiol Infect 2002;128:301-12.

97 Alexandersen S, Donaldson Al. Further studies to quantify the dose of natural aerosols of foot-and-mouth disease virus for pigs. Epidemiol Infect 2002;128:313-23.

\section{Check for updates}

